\title{
El egoísmo en el pensamiento de Thomas Hobbes. Interpretación y racionalidad cooperativa
}

\section{Selfishness in Thomas Hobbes's thought. Interpretation and cooperative rationality}

Diego E. Pinilla-Rodríguez (dpinilla@unach.edu.ec) Universidad Nacional de Chimborazo (Riobamba, Ecuador) https://orcid.org/0000-0002-6663-9478

Patricia Sánchez-Recio (p.sanchezrecio@um.es) Universidad de Murcia (Murcia, España) https://orcid.org/0000-0002-0946-806X

\begin{abstract}
The present article defends the thesis that a plausible conceptualization of egoism in the work of Thomas Hobbes is the one that integrates the possibility of individualistic behaviours that become socially beneficial. To support this thesis, a reconstruction of the concept of egoism is made in Hobbes's work to highlight those interpretations that address the differences between the state of nature and political society. In the latter, through a pact, the interests of others are recognized as part of a strategy that protects their own interests. It is possible to voluntarily protect the welfare of others, even without having any interest in it. Reciprocity and cooperation arise in adaptive processes that establish rules that can represent ideal states of the world and that also maximize self and general interest.
\end{abstract}

Key words: Hobbes, selfishness, own interest, cooperation, rationality.

\section{Resumen}

Se defiende la tesis que una conceptualización plausible del egoísmo en la obra de Thomas Hobbes es aquella que integra la posibilidad de comportamientos individualistas que se hacen socialmente beneficiosos. Con el fin de soportar esta tesis, se hace una reconstrucción del concepto de egoísmo en la obra de Hobbes, para destacar aquellas interpretaciones que abordan las diferencias existentes entre el estado de naturaleza y la sociedad política. En esta última, por medio de un pacto, se reconocen los intereses de los demás como parte de una estrategia que protege los intereses propios. Es posible voluntariamente proteger el bienestar de los demás, incluso sin tener ningún interés en ello. Surge la reciprocidad y la cooperación en procesos adaptativos que establecen reglas que pueden representar estados ideales del mundo y que maximizan el interés propio y general.

Palabras clave: Hobbes, egoísmo, interés propio, cooperación, racionalidad. 


\section{Introducción}

La distinción entre egoísmo y altruismo se utiliza para analizar empírica y analíticamente el comportamiento de los individuos frente a sí mismo y frente a los demás. Siguiendo a Riechmann (La habitación de Pascal), la acción altruista pura sería aquella que beneficia a otros en perjuicio del agente. La acción egoísta pura sería la que, por el contrario, beneficia al agente en perjuicio de otros. Entre estos extremos son identificables otros comportamientos como el actuar en interés propio (beneficio del agente sin perjuicio de otros), la cooperación (beneficio del agente y de otros) o la cortesía (sin perjuicio para el agente con beneficio a otros).

Desde el punto de vista de la racionalidad, el beneficio personal parece prevalecer (egoísmo, interés propio) en tanto que desde la moralidad se exige que la preocupación propia esté al menos al mismo nivel que la preocupación por el bienestar de los demás (altruismo, cooperación, cortesía). Para Sidgwick (The methods of ethics) no es posible negar la individualidad de los sujetos $y$, en consecuencia, es válida su preocupación por la calidad de su existencia sobre la calidad de la existencia de otros individuos. Este sería el hecho fundamental que determina la acción racional de los individuos. Sin embargo, y si esto es correcto, ¿cómo es posible conciliar la acción moral con la acción racional? Si la racionalidad práctica es necesariamente egoísta, ¿cómo podemos motivarnos racionalmente para actuar moralmente? Si el hombre es un ser racional, ¿somos egoístas por naturaleza?

En este sentido, y con el fin de aportar elementos a este debate, se pretende hacer una reconstrucción del concepto de egoísmo en la obra de Thomas Hobbes (1588-1679) a partir de establecer un diálogo entre algunas de sus interpretaciones, a fin de delimitar sus lineamientos generales. Es importante destacar que fue Hobbes el primero dentro de la tradición liberal en abordar la dicotomía entre egoísmo y altruismo, con el fin de construir una explicación de la vida política y social. Por otra parte, Hobbes es reconocido en la teoría filosófica o política por su visión paradigmática de la naturaleza humana como una naturaleza egoísta. Hobbes buscaba una explicación rigurosa, metódica, fundamentada de la naturaleza humana, para comprender las causas de la guerra y las posibilidades de la paz. En términos teóricos pretende comprender la tendencia de los hombres a imponer por la fuerza sus deseos y convicciones, generando una guerra de todos contra todos. Entender las causas posibilitaría tomar las adecuadas acciones correctivas.

Para contestar estas cuestiones, Hobbes parte de un estudio de la naturaleza humana, la cual define por su tendencia a la auto-conservación. Esta característica innata hace que los hombres sean egoístas, esencialmente en su necesidad de supervivencia. El concepto central en Hobbes, la "ley de naturaleza", se define como "un precepto o norma general, establecida por la razón, en virtud de la cual se prohíbe a un hombre hacer lo que puede destruir su vida o privarle de los medios de conservarla; o bien, omitir aquello mediante lo cual piensa que pueda quedar su vida mejor preservada" (Hobbes 2014:106). En otras palabras, el objeto de toda conducta es conservar la vida. El principio de toda actuación, su móvil exclusivo, es la propia conservación biológica. Es el hedonismo individual, un egoísmo natural, el que explica finalmente el comportamiento humano. La felicidad, en este marco, no será otra cosa que el aumento continuo de los medios que permiten satisfacer de forma adecuada las necesidades de la propia conservación. No será el bienestar momentáneo, sino el permanente, el que se desenvuelve de deseo en deseo, el que pretenden todos los seres humanos. 
Por otra parte, y como lo pone de presente Carrillo (Thomas Hobbes y el concepto de estado constitucional de derecho), Hobbes en su estudio de la naturaleza humana también resalta como cada ser humano se percibe como el centro del mundo por la constitución de sus sentidos. Relacionamos y comprendemos todo en relación con nosotros mismos, con nuestra experiencia e intereses. Nuestra naturaleza nos hace percibirnos como el centro del universo, en una situación al extremo personalista. Nuestra configuración natural no es empática, sino que nos condiciona al egoísmo.

Ahora bien, también es cierto que en determinados apartados de su obra Hobbes toma partido por las acciones morales, incluso por encima del interés personal. Al respecto, realiza críticas a quienes siguiendo su propio interés ignoran "el verdadero bien" (Hobbes 2014:83), afirmando incluso que las leyes de naturaleza son "por sí mismas, cuando no existe el temor a un determinado poder que motive su observancia, contrarias a nuestras pasiones naturales, las cuales nos inducen a la parcialidad, al orgullo, a la venganza, y a cosas semejantes" (Hobbes 2014:137). También nos dirá: "considerando que se presume que cualquier hombre hará todas las cosas de acuerdo a su propio beneficio, nadie es árbitro idóneo en su propia causa" (Hobbes 2014:128). Por la misma razón "nadie puede ser admitido como árbitro si para él resulta aparente un mayor provecho, honor o placer, de la victoria de una parte que de la otra" (Hobbes 2014:129).

Distintas interpretaciones intentarán conciliar estos apartados aparentemente contradictorios con el objeto de descifrar de la mejor manera el pensamiento de Hobbes, redefiniendo su concepto de egoísmo. En el presente trabajo se hará una reconstrucción de estas lecturas, en tanto se consideran todas útiles para comprender el proceso mediante el cual, de forma cooperativa, comportamientos individualistas se hacen socialmente beneficiosos. Especialmente son plausibles aquellas interpretaciones que integran al concepto de egoísmo, las diferencias entre el estado de naturaleza y la sociedad política. En esta última, se reconocen los intereses de los demás como parte de una estrategia que protege los intereses propios. Por último, se evidencia cómo esta conceptualización del egoísmo en Hobbes tiene evidentes vínculos con las críticas que siglos después se hicieran a la racionalidad económica instrumental y con el desarrollo de teorías de la acción colectiva, que defienden la posibilidad de considerar la retribución y la cooperación dentro de una racionalidad estratégica superior.

\section{Egoísmo psicológico. Interés propio y lo que apetece}

Se presenta una primera interpretación estándar que descansa en una idea llana atribuida sin matices a Hobbes: un agente solo tiene motivos para actuar en la promoción de su propio interés. Autores como Nagel (Hobbes's concept of obligation) ubican a Hobbes dentro de lo que se conoce como el "egoísmo psicológico", según el cual ningún hombre puede actuar voluntariamente sin tener como objeto su propio bien personal. Es un egoísmo fáctico, descriptivo, un hecho de la naturaleza incontestable: el único motivo para la acción humana es el interés propio. El argumento, como lo reconstruye Feinberg (Reason and responsibility), es que el egoísmo es un hecho psicológico que determina que las personas antepongan su interés propio sin ser capaces de nada más. Los motivos de mi acción voluntaria se igualan a mis propios fines o a mis propios deseos. Esta parece ser la descripción de alguien que podemos denominar egoísta. Si generalizamos este hecho, entonces la humanidad es egoísta por naturaleza. 
Según esta interpretación, para Hobbes actuamos efectivamente a partir de nuestros motivos, que surgen de lo que nos parece beneficioso. La naturaleza humana es egocéntrica y auto motivada. Hobbes sostiene que "nadie da sino con intención de hacerse bien a sí mismo, porque la donación es voluntaria y el objeto de todos los actos voluntarios es, para cualquier hombre, su propio bien" (Hobbes 2014:124). Una versión fuerte diría que las personas siempre actúan en interés propio, aunque puedan ocultar su motivación bajo el ropaje de la ayuda a otros o con el cumplimiento de un deber. Se excluye de este modo todo debate sobre la moralidad, elemento propio de un ejercicio social y problema deliberativo, que nunca entra en conflicto con el interés propio. La moralidad y la virtud no es un asunto de la naturaleza humana.

El egoísmo psicológico también puede describirse como la opinión de que cada acción es causada por un deseo que tiene el agente. Como lo describe Hobbes, estos deseos suelen ser apetitos irracionales que producen una satisfacción a corto plazo. De este modo, la actividad humana está en permanente búsqueda de una felicidad inalcanzable, siempre diferida. La felicidad es "un continuo progreso en el deseo, un continuo pasar de un objeto a otro" (Hobbes 2014:79). En este marco, los hombres buscar afianzar las condiciones que garanticen su felicidad, lo que deriva en una búsqueda "perpetua e incansable" de poder, ya que cuando los hombres obtienen una satisfacción anhelada, otro nuevo deseo surge, produciendo una nueva búsqueda de mayor poder, en un proceso sin fin. Frente a unos bienes escasos, esta búsqueda genera un antagonismo permanente del cual surge la enemistad. Un estado permanente de conflicto, de guerra de todos contra todos. Existe un deseo perpetuo e insaciable de poder que solo cesa con la muerte. El poder asegura el dominio sobre otros, de quienes esperamos aceptación y reconocimiento. La vida es una competencia en donde el ser humano desea siempre tener éxito sobre los demás. El hombre será "un lobo para el hombre".

Cualquiera que sea el objeto de este apetito, será considerado "bueno". Sin embargo, y como lo denota Martinich (Egoism, reason, and the social contract), es posible identificar en Hobbes cierta ambigüedad. No todo lo deseado puede ser bueno, aunque Hobbes parece reflexionarlo en muchos apartados de su obra así. Sin embargo, es posible matizar cierta diferencia entre el interés propio, con lo bueno, con lo que apetece.

Para Gert (Hobbes. Prince of peace), el egoísmo en Hobbes no es la constante actuación en exclusiva por el propio interés, sino por un "deseo egoísta", por el cual se actúa porque algo "es" o "parece" conveniente. Es distinto actuar de acuerdo al propio interés, que actuar de acuerdo con lo que interesa. Ahora bien, del hecho de tener motivos propios, personales, no se puede concluir nada respecto a la naturaleza de estos motivos (Feinberg. Reason and responsibility). A partir de esta idea, es posible verificar la elaboración de otras interpretaciones más complejas.

Por ejemplo, se podría indicar que los hombres llegados a un nivel elevado de razón denotarían la contradicción entre el deseo con el interés propio. El individuo descubre que el egoísmo puro es un estado de conflicto dentro de sí mismo, que le impide realizar su potencial de autorrealización. También evidencia que el egoísmo lo pone en desacuerdo con la sociedad, en la medida en que invita a la venganza, a la hostilidad, al castigo y, en consecuencia, va en detrimento de su propio interés. Por último, el individuo egoísta se coloca fuera del circuito económico a través del cual puede lograr un interés propio pacífico en concierto con otros. 
El egoísmo no es otra cosa que un individualismo problemático que en el fondo se opone al interés propio y los intereses de los demás. Como lo resalta Hobbes, el egoísmo pone a los hombres en desacuerdo consigo mismo al crear un hambre que no puede satisfacerse. Hasta ese punto es una fuente constante de enfermedad. Es un término asociado a necesidades superfluas y extravagantes. Además, implica auto-ganancia a expensas de los demás. Sus medios son inconsistentes con la autorrealización y el interés propio. El potencial humano se cumple a través del propio esfuerzo, sin usurpar lo que legítimamente pertenece a otros.

\section{Interpretación mecanicista}

Décadas atrás, el propio Gert (Hobbes, mechanism, and egoism) proponía otra lectura a partir de un análisis detenido de los argumentos de Hobbes, intentando demostrar que no es necesariamente un egoísta psicológico. Para este autor, es necesario ahondar en el concepto de "motivo". Para tener un motivo se deben cumplir dos requisitos: (a) tener una creencia que proporciona una razón para la acción y (b) que esta creencia sea una explicación adecuada de esta acción. Es posible realizar una determinada acción con un motivo y después concluir que no tenía ningún motivo para hacerlo. Esto sucedería cuando la creencia que cito como mi razón para realizar una acción no brinde una explicación adecuada de la misma.

Ahora bien, el egoísmo psicológico es una teoría de motivos. De acuerdo con el egoísmo psicológico, la explicación adecuada de las acciones humanas se hace en términos de motivos y estos motivos siempre serán motivos de interés propio. El egoísmo psicológico implica que al menos algunas acciones humanas pueden ser adecuadamente explicadas por la creencia de un actor. Si se negara que las creencias, de cualquier tipo, proporcionan una explicación adecuada de la acción humana, entonces se negaría que hay motivos para la acción humana.

Si se sostiene, como hace Hobbes en varios apartados de su obra, que la única explicación adecuada de la acción humana es en términos de "materia en movimiento" (Hobbes 2014:40), se estarían negando los motivos para la acción humana y, en consecuencia, no es posible sostener el egoísmo psicológico. En este sentido, y de acuerdo con la imagen mecánica de Hobbes, toda moción voluntaria (andar, hablar, mover miembros, etc.) es causada por algún cambio en las mociones vitales, es decir, ese movimiento interno que es vital o necesario para la preservación continua (circulación de la sangre, respiración, digestión, etc).

Lo que Hobbes llama "apetito" y "aversión", las causas inmediatas de nuestras acciones voluntarias, no son más que algunos movimientos internos del cuerpo que, por lo general, desconocemos. Hobbes hace una descripción mecánica de la acción voluntaria, incompatible con el egoísmo psicológico. Así, la afirmación: "lo que deseamos, lo deseamos porque beneficia nuestro movimiento vital" en términos hobbesianos se debe interpretar en el sentido de que "lo que deseamos está determinado por sus efectos sobre la moción vital", es decir, que cada vez que algo beneficia nuestra moción vital, esto hace que deseemos esa cosa. En esta interpretación no se dice nada sobre nuestro motivo para desear las cosas que hacemos, solo que hay una relación causal entre algo que beneficia nuestro movimiento vital y nuestro deseo de esa cosa. Del hecho de que cada vez que algo beneficie mi moción vital, hace que lo desee, no se sigue que lo desee porque creo que beneficiará mi movimiento vital. Puede que ni siquiera sepa que la cosa en cuestión 
beneficia mi moción vital y, por lo tanto, esta creencia no podría proporcionarme un motivo para desearlo.

En una interpretación plausible mecanicista Hobbes sostendría que nuestro deseo de algo se debe a que beneficia nuestro movimiento vital, nunca afirma que lo deseamos porque creemos que beneficiará nuestro movimiento vital. De hecho, Hobbes nunca menciona la creencia de que nuestra moción vital será beneficiada, como una razón para desear o hacer cualquier cosa. Se elimina de este modo el primer elemento que configura un motivo: tener una creencia que proporciona una razón para la acción.

Ahora bien, la interpretación mecanicista, aunque interesante, es cuestionable desde varios puntos de vista. El capítulo 6 del Leviatán aborda, es cierto, una perspectiva mecanicista, pero va en contra de todo el resto de los capítulos (por lo menos claramente del 13 en adelante). Baste con leer el capítulo 11 para identificar una relación directa entre estados psicológicos, cognitivos y conativos de los agentes. Por ejemplo, Hobbes dice: "La felicidad es un continuo progreso de los deseos, de un objeto a otro, ya que la consecución del primero no es otra cosa sino un camino para realizar otro ulterior. La causa de ello es que el objeto de los deseos humanos no es gozar una vez solamente y por un instante, sino asegurar para siempre la vía del deseo futuro" (Hobbes 2014:79).

De este modo, la estrategia de adjudicar a Hobbes un enfoque mecanicista para evadir el egoísmo psicológico, simplifica en demasía y hace poca justicia a la complejidad inherente de la mente de los agentes hobbesianos.

\section{Egoísmo de reglas}

Las diferencias entre interés propio y deseo, y las ambigüedades en que parece incurrir Hobbes, han desplegado una versión más sofisticada de la interpretación que se conoce como el egoísmo de reglas (Worsnip. Hobbes and normative egoism). De acuerdo con este punto de vista, Hobbes señala que los motivos para realizar actos se deben ajustar a reglas contrastadas en el largo plazo que maximizan el interés. Se intenta de este modo superar el vínculo del egoísmo con ese deseo irracional que produce satisfacción en corto, intentando reconstruir la relación entre egoísmo e interés propio, por medio de un comportamiento de expectativas adaptativas en el largo plazo.

A veces se tienen motivos para realizar actos que no maximizan el propio interés, pero la idea es seguir reglas contrastadas en el tiempo que si lo hacen. Es una estrategia más efectiva para maximizar el propio interés que tratar de hacerlo caso por caso. Es importante resaltar que la diferencia entre el egoísmo psicológico y el egoísmo de reglas no descansa en que uno tenga en cuenta los efectos en el largo plazo y el otro no. Nada impide que un acto egoísta lo sea teniendo en cuenta sus efectos en el corto o en el largo plazo. Más bien, el contraste surge de considerar seguir una regla, porque su acatamiento a lo largo del tiempo (múltiples ocasiones) maximiza el interés propio del agente. Por el contrario, el egoísmo psicológico solo considera los efectos (en el corto o largo plazo) de un acto individual que se realiza.

En algún sentido, estas reglas podrían considerarse "morales", pero la razón fundamental para cumplirlas no tendrá nada que ver con ninguna idea de deber con los demás. Se seguirá basando en el interés propio. Por lo tanto, los autores que acogen esta interpretación intentan demostrar que 
seguir varias de estas reglas es la forma más racional de buscar el propio interés personal (Gauthier. Thomas Hobbes, Kavka. The rationality of rule-following).

Aquí puede ser útil notar un paralelo entre el egoísmo de reglas y el utilitarismo de reglas (Brandt. Morality, utilitarianism, and rights; Hooker. Ideal code, real world). El utilitarismo de reglas, como se entiende de manera estándar, es la opinión de que solo se deben realizar actos que se describen en una regla que maximiza la utilidad si todos la siguen. En lugar de detenerse en las consecuencias de un acto en particular, se encuentra la mejor regla de conducta a partir de valorar las consecuencias de seguirla. La regla con las mejores consecuencias generales es la mejor regla. Ahora bien, el egoísmo de reglas hace referencia al propio interés de un agente, mientras que el utilitarismo de reglas hace referencia a la utilidad general. El egoísmo de reglas hace referencia a reglas seguidas por un agente individual, mientras que el utilitarismo de reglas hace referencia a reglas seguidas por todos. El fin a ser maximizado ya no será más el deseo o la apetencia, sino el interés propio o el interés general. El mismo puede ser conseguido por actos individuales, reglas seguidas por un agente, o reglas seguidas por todos. Un egoísmo de acto se enfocaría en el agente individual que maximiza su propio interés. Un egoísmo de reglas se enfoca en las normas seguidas por un agente individual que maximiza su propio interés. Un utilitarismo de reglas se enfoca en reglas seguidas por todos y que intenta maximizar el interés general (Worsnip. Hobbes and normative egoism).

\section{Del egoísmo al altruismo por medio del interés propio hasta la reciprocidad}

En las interpretaciones del egoísmo psicológico o el egoísmo de reglas, Hobbes no vincula a la razón en exclusiva con el egoísmo, aunque si señala el dominio del egoísmo sobre el altruismo, el cual queda reducido a un potencial incumplido en el estado de naturaleza. El altruismo no solo está vinculado en exclusiva con la moral, sino que también puede entenderse como una acción racional interesada, en la medida en que, según Hobbes, es esperable una reciprocidad universal. Para Hobbes el altruismo es una preocupación por los demás que tiene consecuencias interesadas. Se refiere a un conjunto de motivos y relaciones entre aquellos cuyos intereses están unidos por un todo social o político más amplio. El tema central es la asistencia mutua que las personas se dan para la defensa común y la preservación de los intereses que comparten. Las acciones altruistas pasan por acciones vinculadas al interés propio. Una acción aparentemente altruista está mediada por la acción interesada de satisfacer el propio deseo (Martinich. Egoism, reason, and the social contract).

En esta lectura, Hobbes vincula al altruismo con el interés propio. No existe independencia entre el interés propio y el interés de los demás, como pareciera exigir el propio concepto de altruismo. Para Hobbes, los seres humanos son por naturaleza egoístas, pero también viven en sociedad, y dado que el egoísmo desenfrenado es socialmente desastroso, existe un interés propio en aceptar leyes que limitan, incluso significativamente, la búsqueda de los deseos libremente escogidos (Graham. Altruism, egoism, and sacrifice). Existe una "buena razón" para hacer lo que la ley nos exige. Así, el altruismo también se hace razón en una construcción social artificial. La esfera de la moral desaparece. Los deseos no se atenúan por restricciones morales, sino por el convencimiento de mi propio interés. El respeto de los intereses de otros proviene de lo artificial-legal, más no es una cuestión natural. La mediación de la ley previene el conflicto, lo que en el fondo es el cuidado racional de mis intereses. 
Profundizando en esta explicación, podemos llegar a la "interpretación de reciprocidad" de Lloyd (Morality in the philosophy of Thomas Hobbes), según la cual es posible identificar en Hobbes la idea de que se actúa en contra de la razón, cuando se hace lo que se juzgaría injustificado en otro. Así, se actúa erróneamente al no acatar recíprocamente los principios a los que los individuos adhieren en una condición particular, explícitamente normativa.

Para Worsnip (Hobbes and normative egoism) la interpretación de la reciprocidad ya es una interpretación "no egoísta". Las leyes de naturaleza no son presentadas como la promoción del propio interés o la autopreservación, sino las bases normativas que permiten justificar mi comportamiento frente a los demás. Es una interpretación radical cuando se afirma que el fin de las leyes de la naturaleza es el bien común y no la preservación o ganancia de un agente individual. Su función es asegurar el bienestar de la humanidad. En otras palabras, las leyes de la naturaleza no son egoístas ni en su fundamento ni en el contenido de sus instrucciones. Su base es la reciprocidad (entendida como justificación mutua) y nos obligan a la búsqueda del bien de la humanidad, incluso sobre lo que podría ser bueno para el individuo.

\section{A medio camino. Del estado de naturaleza a la sociedad política}

Worsnip (Hobbes and normative egoism) ofrece una interpretación que denomina de "medio camino", que considera principalmente las diferencias que existe entre el estado de naturaleza y la sociedad política. En el estado de naturaleza, todas nuestras acciones están basadas en nuestro propio interés, incluso las acciones que nos permitan salir de este estado de naturaleza. Se hace un pacto por interés propio. Una vez hecho el pacto, la obligación es el cumplimiento de este, incluso en contra del propio interés. Se considera que el panorama normativo se altera fundamentalmente en una comunidad política en comparación con el estado de naturaleza. Cada una de las otras interpretaciones del egoísmo intenta ofrecer un principio central que se aplique en ambos estados, y para explicar cómo se debe actuar dependiendo de las circunstancias empíricas particulares. Por el contrario, la interpretación de medio camino considera que, al pactar, se transforma la situación normativa de una en la que solo tenemos razones de interés personal, a una en la que tenemos obligaciones morales propias.

En el estado de naturaleza no existen obligaciones que afecten el interés propio del agente. Al respecto Hobbes dice: "los deseos y las pasiones del hombre no son pecados, en sí mismos; tampoco lo son los actos que de las pasiones proceden hasta que consta que una ley las prohíbe: que los hombres no pueden conocer las leyes antes de que sean hechas, ni puede hacerse una ley hasta que los hombres se pongan de acuerdo con respecto de la persona que debe promulgarla" (Hobbes 2014:103).

Respecto al estado de naturaleza, se reitera: "En esta guerra de todos contra todos, se da una consecuencia: que nada puede ser injusto. Las nociones de derecho e ilegalidad, justicia e injusticia están fuera de lugar. Donde no hay poder común, la ley no existe: donde no hay ley, no hay justicia. En la guerra, la fuerza y el fraude son las dos virtudes cardinales. Justicia e injusticia no son facultades ni del cuerpo ni del espíritu" (Hobbes 2014:104).

Parece claro que en el estado de naturaleza las acciones voluntarias están vinculadas a nuestros intereses propios de auto-conservación, en donde ninguna acción se encuentra prohibida hasta que 
así lo dictamina una ley emitida por un soberano. No es un problema moral, porque la moralidad no existe. Solo lo correcto o incorrecto en términos de mi interés personal. La esfera de las razones normativas no implica ningún tipo de deber u obligación que vaya en contra del propio interés. Las virtudes en el estado de naturaleza son las que conducen a nuestro propio interés. Esas virtudes podrían ser morales en una sociedad ordenada, pero en el estado de guerra son la fuerza y el fraude. La medida del derecho será el interés (Hobbes. Elementos filosóficos sobre el ciudadano).

Respecto a esta postura, que marca una diferencia sustancial entre el estado de naturaleza y la sociedad civil, se podría contra-argumentar lo señalado por Hobbes cuando afirma: "Las leyes de la naturaleza, son inmutables y eternas, porque la injusticia, la ingratitud, la arrogancia, el orgullo, la iniquidad y la desigualdad o acepción de personas, y todo lo restante, nunca puede ser cosa legítima. Porque nunca podrá ocurrir que la guerra conserve la vida, y la paz la destruya" (Hobbes 2014:130).

Para explicar esta aparente discordancia, Worsnip (Hobbes and normative egoism) recuerda una distinción que realiza el propio Hobbes: "Las leyes de naturaleza obligan in foro interno, es decir, van ligadas a un deseo de verlas realizadas; en cambio, no siempre obligan in foro externo, es decir, en cuanto a su aplicación. En efecto, quien sea correcto y tratable, y cumpla cuanto promete, en el lugar y tiempo en que ningún otro lo haría, se sacrifica a los demás y procura su ruina cierta" (Hobbes 2014:130).

Esto indicaría que, de las leyes de la naturaleza, la primera y fundamental es que "cada ser humano debe esforzarse por conseguir la paz mientras quede alguna esperanza de conseguirla" (Hobbes 2014:107), lo que impone un deseo que debe tener lugar. Pero la obligación concreta, en el estado de naturaleza, tendrá lugar cuando sean obedecidas por todos, es decir, cuando se inaugura un orden civil.

Son pocos los casos en los que es posible observar de manera concreta una ley natural en el estado de naturaleza, sin temor en caer en "la ruina". Hobbes señala, por ejemplo, la inutilidad de la crueldad en el estado de naturaleza, ya que puede frustrar las esperanzas de paz. Pero si cualquier agente ve amenazado sus intereses, ya no requiere observar la ley. En otras palabras, las leyes naturales no implican en el estado de naturaleza ningún fundamento para acciones que vayan en contra del propio interés (Worsnip. Hobbes and normative egoism).

De este modo, lo que restringe el absoluto cumplimiento del interés propio en el estado de naturaleza, son las obligaciones in foro externo, o el acto de cumplir con la ley, aún sobre mis intereses. Este fuerte sentido de obligación está ausente en el estado de naturaleza. Las leyes de naturaleza son eternas, pero solo obligatorias en sentido externo, en un orden civil (Worsnip. Hobbes and normative egoism).

El propio Hobbes lo expone claramente: "las leyes de la naturaleza [...] en la condición de mera naturaleza, no son propiamente leyes, sino cualidades que disponen a los hombres a la paz y a la obediencia. Desde el momento en que un Estado queda establecido, existen ya leyes, pero antes no" (Hobbes 2014:219).

Se reitera así la idea de que la entidad de las leyes de naturaleza cambia entre el estado de naturaleza y la sociedad civil, algo que la interpretación del camino medio resalta. 
Pareciera que Worsnip (Hobbes and normative egoism) retorna la interpretación el egoísmo psicológico, pero lo circunscribe al estado de naturaleza. En este, según Hobbes, los hombres ejercen la razón para determinar qué conduce a su propio beneficio, lo que en primer lugar los lleva a buscar la paz. Sin embargo, esta razón no produce "explicaciones correctas" o "deberes genuinos" de mi propio interés, ya que el estándar de razón queda a discreción del propio agente. Al no existir estándar previo e independiente del propio interés, regresamos a la idea de "deseo egoísta", por el cual algo "es" o "parece" conveniente y no puede ser limitado. Derecho es libertad y ley obligación. En el estado de naturaleza tengo el derecho a todo, incluso sobre el cuerpo de otros.

Ahora bien, incluso la obligación de buscar la paz es exigible en la medida en que promueve el interés particular del agente y es acorde con la interpretación del medio camino, que señala que las obligaciones que perjudican el interés del agente sólo son realizables en la sociedad política. Existe un interés privado por buscar la paz y darse un soberano. Serán las sumas de estos intereses privados los que conformen un interés común. Al respecto Hobbes señala: "un hombre se halla en la condición de mera naturaleza (que es condición de guerra), mientras el apetito personal es la medida de lo bueno y de lo malo. Por ello, también, todos los hombres convienen en que la paz es buena, y que lo son igualmente las vías o medios de alcanzarla" (Hobbes 2014:130).

Sin duda, los hombres buscan la paz por un interés privado. Al respecto Hobbes señala: "mientras persiste ese derecho natural de cada uno con respecto a todas las cosas, no puede existir seguridad para nadie (por fuerte o sabio que sea) de existir durante todo el tiempo que ordinariamente la naturaleza permite vivir a los hombres. De aquí resulta un precepto o regla general de la razón en virtud de la cual cada hombre debe esforzarse por la paz, mientras tiene la esperanza de lograrla; y cuando no puede obtenerla, debe buscar y utilizar todas las ayudas de la guerra" (Hobbes 2014:107).

Como señala Worsnip (Hobbes and normative egoism), de varias formas este famoso pasaje indica que es de interés privado y no común el que exhorta a abandonar el estado de naturaleza. Las leyes de naturaleza son descubiertas por la razón de cada uno de los individuos, que le prohíben hacer aquello que pueda ser destructivo para cada vida en particular. No hay razón para interpretar la regla enunciada por Hobbes como la búsqueda de un bien común, ya que no hay un bienestar general como fin. Se reitera cómo el altruismo está sometido al egoísmo en el estado de naturaleza. En este estadio no existe una obligación universal o un razonamiento moral. No se conjuga el verbo "deber" o "hacer" en plural. Toda obligación moral en el estado de naturaleza es egoísta.

Las leyes naturales que se establecen como reglas generales (recíprocamente) fomentan, ante todo, un interés egoísta. Hobbes lo indica claramente cuando afirma que: "Las pasiones que inclinan a los hombres a la paz son el temor a la muerte, el deseo de las cosas que son necesarias para una vida confortable, y la esperanza de obtenerlas por medio del trabajo. La razón sugiere adecuadas normas de paz, a las cuales pueden llegar los hombres por mutuo consenso. Estas normas son las que, por otra parte, se llaman leyes de naturaleza" (Hobbes 2014:105).

Las leyes de naturaleza promueven pasiones individuales, no un bien común trascendente. La razón no anula nuestras pasiones. Sugiere maneras de realizarlas mejor, incluyendo la idea de no hacerlo de manera descoordinada. De ahí la importancia del acuerdo mutuo. Si todos acordamos reglas vinculantes, podemos realizar nuestras pasiones mejor. La ganancia que todos obtienen supera las pérdidas individuales en las que se pueda incurrir. 
De este modo, la primera ley de la naturaleza es un caso especial, porque si se sigue con éxito (de manera egoísta) en el estado de naturaleza, saldremos del mismo, donde esta y las otras leyes de la naturaleza se hacen vinculantes. En general, carecemos de la capacidad de hacer convenios en el estado de naturaleza, porque no se pueden hacer cumplir. La única excepción es un pacto para dejar el estado de naturaleza (que crea las condiciones para su propia aplicación). Al entrar en una sociedad civil, el pacto hace que el cumplimiento sea posible, legítimo.

Una vez que hacemos parte de una comunidad política, es necesario efectuar acciones que incluso perjudican el interés propio. Se establece un sistema de cooperación que, para mantenerse, requiere de la observación de las leyes de naturaleza, leyes que se ha convenido cumplir y que limitan la libertad natural del hombre: "La libertad natural del hombre, puede ser limitada y restringida por la ley civil [...] de tal modo que no pudieran dañarse sino asistirse uno a otro y mantenerse unidos contra el enemigo común" (Hobbes 2014:220). En síntesis, deponemos nuestros derechos por razones egoístas, para asumir obligaciones no egoístas con nuestros conciudadanos. Sobre el mecanismo, nos dice Hobbes: "Cuando una persona ha abandonado o transferido su derecho por cualquiera de estos modos, dícese que está obligado o ligado a no impedir el beneficio resultante a aquel a quien se concede o abandona el derecho. Debe aquél, y es su deber, no hacer nulo por su voluntad este acto. Si el impedimento sobreviene, prodúcese injusticia o injuria, puesto que es sine jure, ya que el derecho se renunció o transfirió anteriormente" (Hobbes 2014:108).

La determinación y los límites de nuestros derechos se configuran por razones egoístas. Sin embargo, las obligaciones que surgen de nuestros propios derechos van más allá del egoísmo. Las interpretaciones del egoísmo psicológico o de reglas, indicarían que la obligación de observar las leyes naturales depende del cumplimiento del propio interés. En este sentido, no se podría establecer una obligación correcta o natural. Es de interés propio realizar un pacto, que crea obligaciones que posteriormente no se pueden excusar por el interés propio. Ser parte de una comunidad y aceptar sus beneficios, implica un consentimiento tácito.

Al final, lo que diferencia entre una obligación legítima o no, no es la adecuación con mi propio interés. La diferencia surge de mi compromiso de mantener los fines que he adquirido por medio de un pacto, confiando en él para mi propia protección. Es reconocer los intereses de los demás como parte de una estrategia que protege mis intereses, que no es lo mismo que respetar simplemente las necesidades de otros. Es posible voluntariamente proteger el bienestar de los demás, incluso sin tener ningún interés en ello.

\section{Cooperación y elección social}

Los debates respecto al concepto de egoísmo en autores como Hobbes, sin duda, son de la misma naturaleza que las reflexiones adelantadas siglos después por variadas teorías políticas y económicas. Problemas como la provisión de bienes públicos, la elección social, la economía general del bienestar, etc., son claros ejemplos de cómo se intentan integrar los procesos de decisión económica y política. Por ejemplo, Arrow (Social choice and individual values) declararía en un famoso teorema la imposibilidad de que bajo ciertas condiciones se puedan agregar las preferencias individuales en forma de preferencias sociales. Es decir, para este autor, no es posible conciliar los deseos personales a fin de que conformen reglas sociales. 
La racionalidad económica instrumental restringe en demasía el comportamiento económico a un solo supuesto ético: el propio interés personal. El sujeto es racional si elige aquel curso de acción que maximiza su interés privado a partir de un conjunto de preferencias consistentes (Aguiar. Intereses individuales y acción colectiva). No es difícil ver el paralelismo con las interpretaciones del egoísmo psicológico y su idea de que un agente solo tiene motivos para actuar, esto es, la promoción de sus deseos o de su propio interés.

Al respecto, y reflexionando sobre el crecimiento sostenible, Jackson (El reto de un mundo sostenible) acude a la psicología evolutiva para responder a la pregunta si la competición por la supervivencia, el status y el consumismo son efectivamente algo "natural". Se indica que es posible identificar una raíz ancestral a los deseos humanos, que se resume en la necesidad de transmisión genética, algo que depende de dos factores: la supervivencia hasta la edad reproductiva y encontrar pareja. La naturaleza humana parece estar destinada a la competencia por los recursos materiales, sociales y sexuales, que le permita lograr estos dos objetivos. Con el agravante, ya identificado por Hobbes, que dicha competencia nunca se acaba, nunca nos adaptamos a un nivel de satisfacción. La felicidad es "un continuo progreso en el deseo, un continuo pasar de un objeto a otro" (Hobbes 2014:79). Es evidente en los procesos sociales, y más específicamente los mercantiles, la relación entre lo material y el deseo, o el consumismo y el sexo, o la supervivencia y el status social. Si esto es cierto, los individuos no tendrán ningún incentivo para el altruismo, por ejemplo, contribuir en la provisión de bienes públicos. Si lo hacen, su comportamiento se calificaría como irracional. Deben intentar no participar en la provisión, pero si aprovecharse de quienes si lo hacen.

Frente a estas ideas que reducen al ser humano a su condición biológica, limitada en una estricta racionalidad instrumental y hedonista, Hobbes denunciaría a este egoísmo como un individualismo problemático que en realidad se opone al interés propio. El individuo egoísta ciertamente es aquel que se coloca fuera del circuito económico a través del cual logra su interés propio, al negarse a cooperar con otros. Son varios los ejemplos, reales o ficticios, en donde acciones individuales y perfectamente racionales (en términos instrumental - egoístas) conducen a resultados colectivamente desastrosos. La metáfora de la tragedia de los comunes (Hardin. The tragedy of commons) es un conocido ejemplo según el cual varios sujetos, motivados por su interés particular y actuando racional e independientemente, destruyen por sobreexplotación un recurso limitado compartido.

La consecuencia de la perspectiva egoísta psicológica parece anticipada por Hobbes: la intervención centralizada pública se ve justificada. Los sujetos en un ejercicio racional y voluntario se someten a la coacción de un Estado que limita sus apetitos e intereses (Baumol. Welfare economics and the theory of state). Dicha idea se expresa en la interpretación del "medio camino" de Hobbes. En el estado de naturaleza, las acciones voluntarias están vinculadas a nuestros intereses propios de autoconservación, en donde ninguna acción se encuentra prohibida hasta que así lo dictamina una ley emitida por un soberano. Existe un interés privado por buscar la paz y darse un soberano, un poder común por encima de los poderes de los individuos, que sea suma autoridad y árbitro equitativo entre sus intereses en conflicto. Un poder que todos se puedan sentir forzados a obedecer, porque lo pueden también reconocer como única condición de justicia y, por tanto, de una paz efectiva. Todos se someten a una sola ley que todos pueden conocer y comprender con claridad, para que puedan obedecerlas con responsabilidad. 
De todas formas, esta solución parece seguir siendo insuficiente. El modelo de egoísmo psicológico o de reglas remite a una idea de sujeto muy limitada. Se considera a un hombre racional económicamente (en la protección de sus intereses personales), pero inútil en términos sociales, que le hace requerir un dictador. Sin embargo, es posible realizar descripciones más plausibles del accionar humano, por ejemplo, enriqueciendo el contenido de sus preferencias. Es necesario ampliar el rango de sus posibles motivaciones, a fin de incluir la cooperación o las motivaciones sociales (Sen. Rational fools). En conclusión, aceptar la posibilidad de una racionalidad superior, capaz de imponerse límites.

Sin duda Hobbes ya apuntaba en esta dirección. Recrimina el comportamiento de motivación en exclusiva individualista, basado en el deseo de la satisfacción inmediata. Una razón de cierto nivel diferencia entre lo que parece conveniente, frente a lo que realmente lo es. Que sean mis motivos, no quiere decir que sean los correctos. En este sentido, el interés propio (a diferencia del deseo), remite a una justificación plausible de las acciones a partir de criterios que, si bien no son de origen social en Hobbes, sí aspiran a la universalidad a partir de la reciprocidad.

Las teorías de la acción colectiva (Olson. The logic of collective action) avanzan en esta idea de acciones individuales cuya justificación es social en origen. Arrow (Social choice and individual values) apunta a la necesidad de un cambio en la fundamentación de la acción y en la percepción del proceso de elección. Nuestras motivaciones no serán canastas de mercancías, sino estados sociales o estados del mundo, que comprometen al individuo y a su entorno. Esta modificación de objeto de elección implica un cambio radical: la ordenación de las preferencias no depende de las apetencias racionales de los individuos, sino de sus valores. Los estados del mundo escapan a la valoración meramente instrumental, lo que no impide que puedan ser comparados o debatidos intersubjetivamente.

Una "interpretación de reciprocidad" de Hobbes también entendería atentatorio de la razón actuar de una forma que se consideraría injustificada en otro. Existe un deber de acatar recíprocamente ciertos principios a los cuales los individuos adhieren y que sin duda son de origen social. No actuamos por necesidades o deseos, sino por el cumplimiento de un mundo ideal. Un estado social que involucra reglas generales, que nadie puede violar justificadamente. Sin duda, las teorías de la acción colectiva o las interpretaciones de reciprocidad refieren a acciones no egoístas. Mi comportamiento se debe ver justificado en un bien común que se acredita mutuamente y que incluso puede prevalecer sobre los intereses de los individuos.

La reciprocidad sin duda también refiere a la posibilidad de superar la racionalidad egoísta hacia una racionalidad estratégica que posiciona al individuo, ya no aislado y exclusivamente ante una canasta de bienes en un momento específico, sino también de cara a otros individuos, dentro de unas reglas preestablecidas y en múltiples interacciones. Esta racionalidad ampliada exige a los individuos que anticipen decisiones y preferencias de otros, que afectan la posibilidad de cumplir mis intereses propios.

Nos encontramos en el campo de la teoría de juegos. La consecución de las preferencias individuales depende de la consecución de las preferencias de todos, ya sea por motivaciones que van desde el egoísmo hasta el altruismo. La consecución de las preferencias depende de la acción de todos los involucrados a través de una causalidad social general. La acción de cada sujeto depende de la 
acción de todos los demás, por razonamiento estratégico. A partir de estos supuestos, de busca un punto de equilibrio donde las distintas estrategias se hacen óptimas unas frente a otras. La solución del juego es un punto de equilibrio hacia el cual convergen tácitamente todos los individuos (Elster. Uvas amargas).

Como señala Martínez (Hobbes y la moral egoísta en el estado de naturaleza), esta aproximación está relacionada con los argumentos de Hobbes. Actuar en contra de lo pactado puede parecer en un primer momento adecuado para realizar el interés personal. Al respecto Hobbes señala que dicha actitud es contraria a la razón, ya que lo prudente es mantenerlo y cooperar, dada la expectativa de interacciones futuras frente a los demás.

\section{Conclusiones}

Las distintas interpretaciones del egoísmo en Hobbes ayudan a comprender el proceso mediante el cual, de forma cooperativa, comportamientos individualistas se hacen socialmente beneficiosos. La primera idea para resaltar es que el accionar humano (económico o político) configura procesos históricos, adaptativos, de prueba y error, que funcionan de manera socialmente provechosa a partir no solo del interés individual, sino además por el establecimiento de reglas del "juego limpio" que permiten prever el comportamiento de los demás individuos.

Tratar de maximizar exclusivamente el bienestar individual produce un resultado no óptimo: un menor bienestar personal al tener que dedicar recursos a resolver la incertidumbre, cuidar la vida o cuidar la propiedad. La producción y el intercambio solo son posibles sobre la base de acuerdos previos y soluciones cooperativas que resultan más eficientes que las exclusivamente competitivas. Existen comportamientos generalizados basados en normas sociales, que desplazan los comportamientos maximizadores individuales y no cooperativos.

Sobre un pacto de origen privado, pero universal y retributivo, es posible considerar acciones colectivas por el bienestar público. No existen dos funciones de utilidad (individual y social), sino una sola, compuesta por distintos órdenes de preferencias (desde el egoísmo, pasando por la simpatía y llegando al compromiso) que se disponen según la moral y la eficacia presentes en las actitudes del individuo (Sen. Choice, orderings and morality).

\section{Bibliografía}

Hobbes, T. (2014). Leviatán. La materia, forma y poder de una república eclesiástica y civil. Fondo de Cultura Económica.

Recibido el 31 Ago 2020

Aceptado el 2 Oct 2020 